\title{
Comprehensive Interaction Model for Cloud Management
}

\author{
Md. Nasim Adnan ${ }^{1}$ \\ Department of Computer Science and Engineering \\ Jashore University of Science and Technology \\ Jashore-7408, Bangladesh
}

\author{
Md. Majharul Haque ${ }^{2}$, Abu Sadat Mohammad Yasin ${ }^{5}$ \\ Muhammad Shakil Pervez ${ }^{6}$ \\ Bangladesh Bank, Dhaka, Bangladesh
}

\author{
Mohammad Rifat Ahmmad Rashid ${ }^{3}$ \\ University of Liberal Arts Bangladesh \\ Dhaka, Bangladesh
}

\author{
Mohammod Akbar Kabir ${ }^{4}$ \\ Department of Economics \\ University of Dhaka, Dhaka, Bangladesh
}

\begin{abstract}
Cloud computing is readily being adopted by enterprises due to its following benefits: ability to provide better service to customers, improved flexibility, lower barrier to entry for an enterprise, lower maintenance cost on IT service, availability etc. However, the interaction between cloud service provider and customer is not well-defined yet. Understanding of the service offered while approaching cloud computing paradigm and also understanding of the required actions during the period of receiving a cloud service e.g. provision of new resources, scaling up/down, billing, etc. remains a concern for the enterprises. This paper proposes a segregated interaction model to manage the receiving of a cloud service in a hierarchical way.
\end{abstract}

Keywords-Cloud computing; cloud management; cloud customer

\section{INTRODUCTION}

This Nowadays the concept of a cloud computing is one of the emerging issues in the domain of Information Technology (IT) service industry [1], [2]. Cloud computing [3], [4] is the realization of a long-held desire to offer computing (e.g. networks, servers, storage, and application services) as a service like other utilities e.g. electricity, gas, water etc. It offers a an array of solutions and advantages to business with increased flexibility, scalability and agility with reduced procedural, administrative, hardware and software costs and with higher efficiency [4], [5]. Due to these benefits, the growth in adoption of cloud has been phenomenal [6]. Gartner has the forecast that the cloud computing industry is poised for strong growth through 2014, when worldwide cloud services revenue is projected to reach $\$ 148.8$ billion [7].

Cloud computing enables us to enroll into subscriptionoriented services in a "pay-as-you-go" manner by leasing IT capabilities through the Internet. As a result, new entrepreneurs no longer require investing capital for IT Infrastructure. Instead, they can take the opportunities of provisioning of resources based on usage requirement and pay based on consumption. Thus, entrepreneurs can transfer risks and maintenance aggravation at the cost of converting capital expenses to operational expenses. Cloud computing also gives an illusion of ample resources available on demand for enormous scalability. Cloud computing has been defined by many thinkers and experts in many different ways. Among them, we will use the definition given by National Institute of Standards and Technology (NIST). According to NIST: "Cloud Computing is a model for enabling ubiquitous, convenient, ondemand network access to a shared pool of configurable computing resources (e.g. networks, servers, storage, applications, and services) that can be rapidly provisioned and released with minimal management effort or service provider interaction” [8].

A cloud can be public or private. A private cloud is behind the company firewall and is not avaiable to external entity whereas in a public cloud system (Fig. 1), general public or external enterprises can get computing services as utility. This public cloud now triggers the need for cloud service management on the receiving side, which is addressed by this paper. On the other hand, cloud service providers consider service delivary model e.g. Insfrastructure as a Service (IaaS), Platform as a Service (PaaS), Software as a Service (SaaS) and manage cloud by employing differernt management models e.g. consumer utilization model to maximise their utilization and hence profit [9], [10].

Many people are aware of the concept of cloud but do not have a clear understanding of the management of receiving a cloud service and thus reluctant to adopt the cloud. On the other hand, many people already have shifted to cloud but unable to gain a real benefit of being in the cloud due to absense of a proper approach. This paper offers a comprehensive interaction model for cloud customers covering the enitre interaction scenarios by using a set of use cases, so that users can approach cloud with a systematic way and can realize maximum benefits from cloud.

The remainder of the paper is structured as follows: Section 2 provides an anatomy of services provided by a cloud. A breakdown of a cloud system with a mapping to use cases is provided in Section 3. In Section 4, an interaction model for cloud management is proposed. Finally, Section 5 provides some useful concluding remarks. 


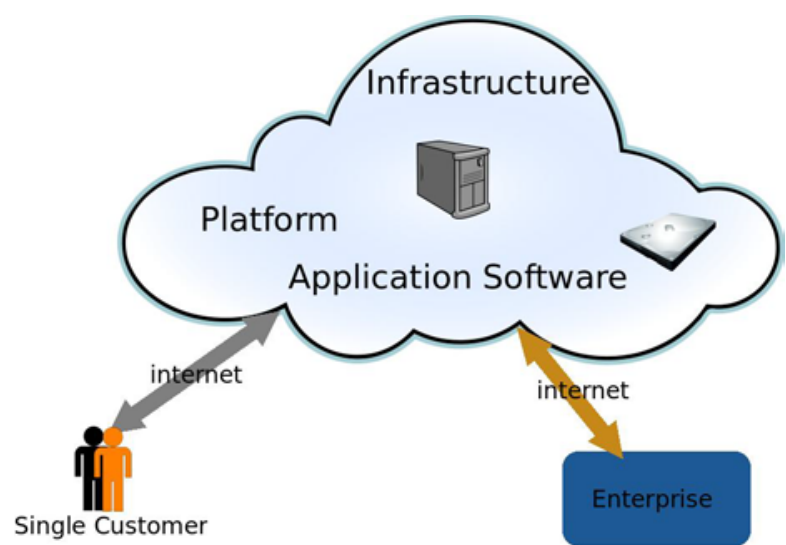

Fig. 1. A Public Cloud.

\section{Cloud Service}

To manage a cloud, it is very essential to obtain an understanding of a typical cloud service. A cloud service is similar to a recurring business activity. A cloud user can get one or more services for a period of time, from one or multiple cloud providers. Cloud providers may charge cloud customer for their contract/consumption of resources by hour, month or year. Cloud service is defined by the Open Group as: "A service is a logical representation of a repeatable business activity that has a specified outcome, is self-contained, may be composed of other services" [11].

A cloud service is initiated, when a cloud provider makes an offering of a cloud service and makes it available for potential customers. A service is ended, when the particular service is no longer available for any customer. A typical cloud service has five states in its lifecycle (see Fig. 2):

- Available: When a cloud provider makes an offering of a service along with associated cost, policies, etc. and makes it available for potential customers.

- Contract: When cloud customer(s) make contract to get a service.

- Runtime Maintenance: Cloud provider deploys resources for customer(s) as per contract i.e. makes the resources available for the customer(s) and manages the resources.

- End of Contract: When cloud customer(s) terminate the contract for the service.

- Unavailable: When the cloud provider(s) or other external event(s) make the service unavailable.

Now, consider a scenario of a business organization, where IT infrastructure is required. If the organization invests on IT infrastructure more than the actual demand, then a part of the capital is wasted, whereas having less of IT capability will hamper business growth. These businesses can take the benefit of cloud by leasing IT capabilities in a systematic approach. Moreover, demand of IT infrastructure varies with time; some business face periodic demand, some face very high demand for a short period of time. Some of the common features of IT demand are shown in Fig. 3. Instead of leasing a constant IT capability, an organization can realize a tailored service(s) by following a usage pattern from old consumption data in a cloud. To realize the full benefit of being in cloud, users should be aware of all the functionalities within the system boundary and this can be achieved by following a model like we propose in this paper.

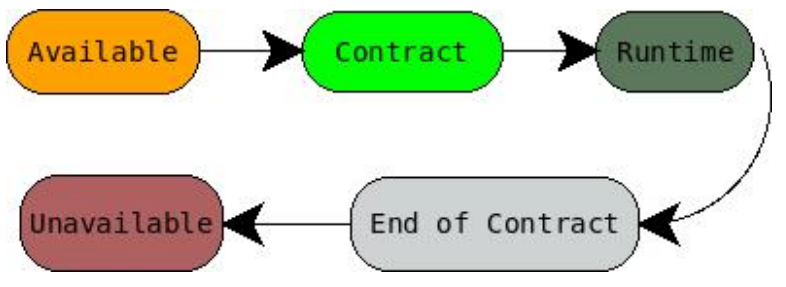

Fig. 2. Lifecycle of a Cloud Service.
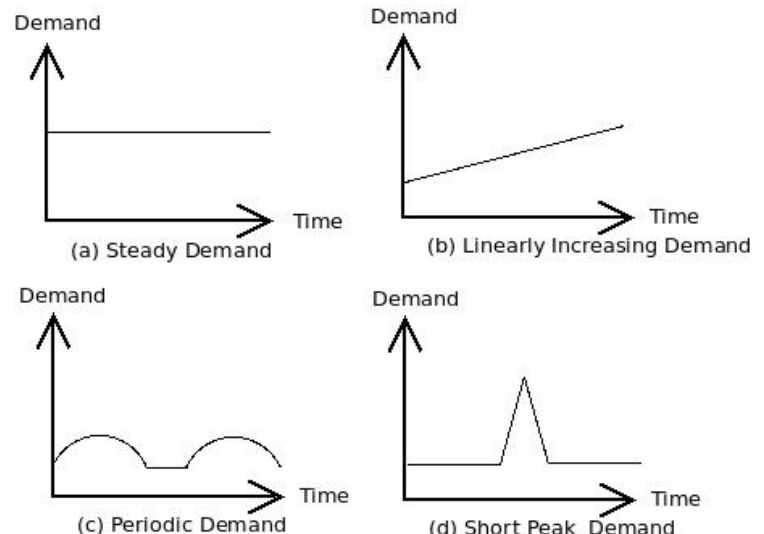

Fig. 3. Some Common usage Patterns.

\section{USE CASE}

Use cases [11] are very useful to capture and communicate the functional characteristics of a system in a clear and easy way without internal details. It is a list of steps defining who does what and thus it describes the interactions between stakeholders and helps to achieve the system goal(s). A complete set of use cases can describe all the different ways to use the system and bounds the system scope. In a use case, a stakeholder is represented as an actor.

1) Actors: In a system, an entity that is able to make decisions is represented as an actor which may not necessarily be a human. In cloud system, there are two high level actors: Cloud User and Cloud Provider.

2) Cloud user: Cloud user is the representation of a person or company, who consumes cloud-based service(s) and pays in return and triggers the need for effective cloud usage management.

3) Cloud provider: Cloud provider is a representation of a company, who provides cloud-based services (infrastructure, platform, application software, etc.).

In the proposed interaction model, we have two low level actors in each high-level group: Business Manager (for business decision making) and Technical Manager (for technical decision making) as shown in Fig. 4. In the proposed model, we use the term "customer" to represent an entity that pays for receiving cloud services while user is the superset of customer. 


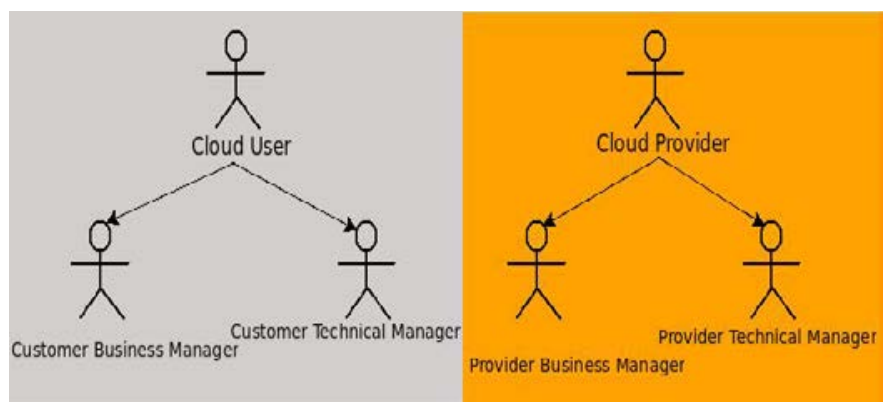

Fig. 4. Classification of Actors in a Cloud System.

\section{INTERACTION MODEL}

We have already defined the actors in the previous section. Now, we will define the roles of the actors to describe all the functions in a cloud system. The system functions can be categorized into three groups: business contract level, operational level and feedback level functions. In business contract level, we will describe the system functions that are attached with legal bindings. The system functions that are actually used to receive a cloud service are grouped into operational level, whereas feedback level functions feed into business contract level so that business contracts can be done or changed in an optimal way. A complete and comprehensive set of use cases are shown in Fig. 5.

\section{A. Business Contract Level Functions}

Establish Relationship: It is essential for a cloud provider to be certain of the identity of the cloud customer and provide it with security credentials (Table I).

Establish Contract: Cloud customer and provider should enter into legal bindings before providing or receiving any service. Cloud Service level Agreements (SLA) acts as a key liaison between consumers and providers on renting Anything as a Service (AaaS) [12]. In this stage, an SLA is agreed upon by both parties (Table II). Due to the dynamic nature in cloud, continuous monitoring on Quality of Service (QoS) characteristics is essential to administer SLAs [13]. While preparing SLA, the following points should be considered from the cloud customer point of view:

a) Everything should be written in SLA.

b) There must be a certain guarantee of performance such as service availability, response time, etc. and there must be a financial penalty in presence of failure to meet such performance level.

c) The licensing of required software(s) must be explicitly defined.

d) It is better to get service from multiple vendors to avoid vendor lock-in.

e) The time required to provision resources must be included in SLA.

f) Data ownership, confidentiality, auditability must be defined and the vendor must return data in case of change in vendor.

g) There must be provisions for change (Table III) and terminate (Table IV) the contract.

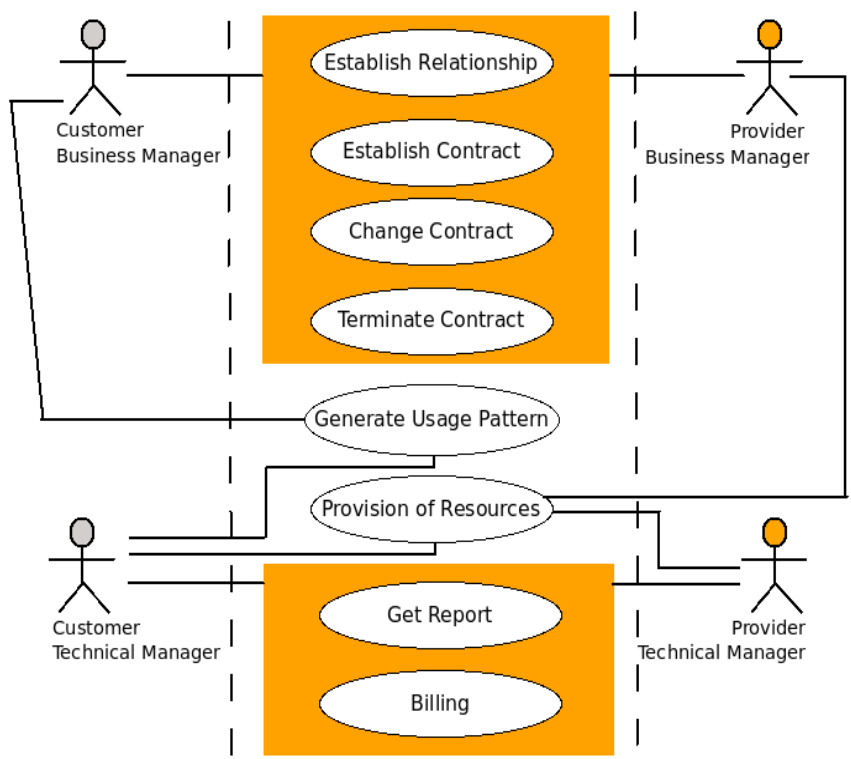

Fig. 5. A Comprehensive Set of use Cases Defining System Boundary.

\section{B. Operational Level Functions}

Provision of Resource: By using this function, a cloud customer can reserve resources for its use within the limit mentioned in the SLA and these resources are kept aside for the particular customer until the resources are released (Table V).

Get report: Cloud customer gets a report on the resource consumption to use it for internal purpose and also these reports are used to find a pattern in its usage (Table VI).

Billing: Cloud customer gets an invoice for billing and makes the payment (Table VII).

TABLE I. USE CASE TO ESTABLISH RELATIONSHIP

\begin{tabular}{|l|l|l|}
\hline Use Case 1 & Establish Relationship \\
\hline Description & $\begin{array}{l}\text { A potential customer of a cloud-related service wants to } \\
\text { establish an identity with a cloud service provider and } \\
\text { gets security credential in return. }\end{array}$ \\
\hline Goal in context & The customer have an identity with the cloud provider. \\
\hline Actors & $\bullet \quad \begin{array}{l}|c| \\
\text { Provider Business Manager (PBM) }\end{array}$ \\
\hline Preconditions & None \\
\hline Trigger & \begin{tabular}{l} 
Business needs of a customer Business Manager (CBM) \\
\hline Scenarios
\end{tabular} & $\begin{array}{l}\text { Scenarios Details } \\
\text { Exchanged }\end{array}$ \\
\hline & $\begin{array}{l}\text { CBM Browses the } \\
\text { services offered by cloud } \\
\text { provider. }\end{array}$ & Service catalog \\
\hline & $\begin{array}{l}\text { PBM asks for security } \\
\text { credential. }\end{array}$ & None \\
\hline Exceptions & $\begin{array}{l}\text { CBM provides identity, } \\
\text { bank details etc. }\end{array}$ & $\begin{array}{l}\text { None } \\
\text { with the security } \\
\text { credntial. }\end{array}$ \\
\hline & \begin{tabular}{l} 
The process can be done offline or online. \\
\hline
\end{tabular} & Security token \\
\hline
\end{tabular}


TABLE II. USE CASE To ESTABLISH A SERVICE CONTRACT

\begin{tabular}{|c|c|c|}
\hline Use Case 2 & \multicolumn{2}{|l|}{ Establish a Service Contract } \\
\hline Description & \multicolumn{2}{|c|}{ A potential customer of a cloud-related service wants to establish a contract with a cloud service provider. } \\
\hline Goal in context: & \multicolumn{2}{|c|}{$\begin{array}{l}\text { The customer enters into a legal binding with the cloud service provider as per Service Level Agreement (SLA) with sufficient } \\
\text { technical and business information. }\end{array}$} \\
\hline Actors & \multicolumn{2}{|l|}{$\begin{array}{ll}- & \text { Provider Business Manager (PBM) } \\
\text { - } & \text { Customer Business Manager (CBM) } \\
\end{array}$} \\
\hline Precondition: & \multicolumn{2}{|c|}{$\begin{array}{l}\text { Customer Business Manager has established identity with Provider and can login in the interface provided by the cloud service } \\
\text { provider. }\end{array}$} \\
\hline Trigger & \multicolumn{2}{|l|}{ Business need to start receving of a cloud service. } \\
\hline \multirow[t]{5}{*}{ Scenarios } & Scenarios Details & Data or Artifacts Exchanged \\
\hline & CBM logs in. & Security credential \\
\hline & CBM selects the intended service. & None \\
\hline & PBM informs the associated terms and conditions. & Proposed SLA \\
\hline & CBM agrees to the proposed SLA and enters into legal bindings. & SLA \\
\hline Exceptions & \multicolumn{2}{|l|}{ It can be done offline or online. } \\
\hline
\end{tabular}

TABLE III. USE CASE TO CHANGE CONTRACT

\begin{tabular}{|c|c|c|}
\hline Use Case 3 & \multicolumn{2}{|l|}{ Change Contract } \\
\hline Description & \multicolumn{2}{|c|}{ Initiated either by cloud customer or provider and agreed by both, their legal responsibilities changes. } \\
\hline Goal in context & \multicolumn{2}{|c|}{ Both the cloud customer and provider agree and make changes to SLA if allowed within the SLA. } \\
\hline Actors & \multicolumn{2}{|l|}{$\begin{array}{ll}- & \text { Provider Business Manager (PBM) } \\
- & \text { Customer Business Manager (CBM) } \\
- & \text { Provider Technical Manager (PTP) } \\
\end{array}$} \\
\hline Precondition & \multicolumn{2}{|c|}{ The customer is already in a legal binding with the cloud service provider. } \\
\hline Trigger & \multicolumn{2}{|l|}{ Business need to change the service received. } \\
\hline \multirow[t]{5}{*}{ Scenarios } & Scenario Details & Data or Artifacts Exchanged \\
\hline & CBM logs in. & Security credential \\
\hline & $\begin{array}{l}\text { Change configurations in SLA and submits for approval } \\
\text { by PBM. }\end{array}$ & SLA \\
\hline & CBM is notified with the reply from PBM. & SLA \\
\hline & If PBM agrees, then PTP apply those changes. & None \\
\hline Exceptions & \multicolumn{2}{|c|}{$\begin{array}{l}\text { - } \quad \text { CBM and PBM can terminate the existing SLA and create a new one. } \\
\text { - } \quad \text { PBM can also initiate to change SLA. }\end{array}$} \\
\hline
\end{tabular}

TABLE IV. USE CASE TO TERminAte CONTRACT

\begin{tabular}{|c|c|c|}
\hline Use Case 4 & \multicolumn{2}{|l|}{ Terminate Contract } \\
\hline Description & \multicolumn{2}{|c|}{ Initiated either by cloud customer or provider their contract cease to exit. } \\
\hline Goal in context: & \multicolumn{2}{|c|}{$\begin{array}{l}\text { Both the cloud customer and provider agree to terminate the contract. The resources kept for that particular customer is freed and ready to be } \\
\text { allotted to other customers. }\end{array}$} \\
\hline Actors & \multicolumn{2}{|c|}{$\begin{array}{ll}- & \text { Provider Business Manager (PBM) } \\
- & \text { Customer Business Manager (CBM) } \\
\end{array}$} \\
\hline Precondition & \multicolumn{2}{|c|}{ The customer is already in a legal binding with the cloud service provider. } \\
\hline Trigger & \multicolumn{2}{|c|}{ CBM no longer requires the cloud service. } \\
\hline \multirow[t]{5}{*}{ Scenarios } & Scenarios Details & Data or Artifacts Exchanged \\
\hline & $\begin{array}{l}\mathrm{CBM} / \mathrm{PBM} \text { logs in and request for } \\
\text { termination of contract. }\end{array}$ & Security credential \\
\hline & Another party agrees. & None \\
\hline & Contract gets null and void. & None \\
\hline & $\begin{array}{l}\text { There can be provision of penalty for } \\
\text { immature termination of SLA. }\end{array}$ & \\
\hline Exceptions & \multicolumn{2}{|c|}{$\mathrm{CBM} / \mathrm{PBM}$ logs in and request for termination of contract. } \\
\hline
\end{tabular}


TABLE V. USE CASE to PROVISION OF RESOURCES

\begin{tabular}{|l|l|l|}
\hline Use Case 5 & Provision of Resources \\
\hline Description & Cloud customer makes a reservation of resources wihtin the limit set by SLA. \\
\hline Goal in context & Cloud provider sets aside resources to be consumed by the cloud customer. \\
\hline Actors & $\begin{array}{l}\boldsymbol{\bullet} \quad \text { Provider Technical Manager (PTM) } \\
\text { Customer Technical Manager (CTM) }\end{array}$ \\
\hline Precondition: & Cloud customer and provider have a SLA and the requested amount and type of resources is permitted according to SLA. \\
\hline Trigger & Business requirements to use resources through a cloud service. & \multicolumn{2}{|l}{} \\
\hline Scenarios & Scenarios Details & Data or Artifacts Exchanged \\
\hline & CTM logs in. & Security credential \\
\hline & CTM requests for resources. & Service \\
\hline & $\begin{array}{l}\text { PTM checks against the SLA and makes necessary } \\
\text { arrangements to reserve requested resources. }\end{array}$ & None \\
\hline Exceptions & CTM is notified about the result & None \\
\hline
\end{tabular}

TABLE VI. USE CASE TO GET CONSUMPTION REPORT

\begin{tabular}{|l|l|l|}
\hline Use Case 6 & Get Consumption Report \\
\hline Description & Cloud provider sends a detailed report of the consumption by the cloud customer. \\
\hline Goal in context: & Cloud customer gets detailed informations about the consumption of resources by itself. \\
\hline Actors & $\bullet \quad$ Provider Technical Manager (PTM) \\
\hline Precondition: & Cloud customer Technical Manager (CTM) & Data or Artifacts Exchanged \\
\hline Trigger: & To have an updated status of the usage. & Security credential \\
\hline Scenarios & Scenarios Details & None \\
\hline & CTM logs in and request for consumption report. & None \\
\hline & PTM provides consumption report by using historic data. & \\
\hline & CTM observes the detailed report on the consumption of resources. & \\
\hline Exceptions & None & CTM logs in and request for consumption report. \\
\hline
\end{tabular}

TABLE VII. USE CASE TO BILLING

\begin{tabular}{|c|c|c|}
\hline Use Case 7 & \multicolumn{2}{|l|}{ Billing } \\
\hline Description & \multicolumn{2}{|c|}{ Cloud provider sends an invoice as a charge for the consumption/contract of the cloud customer and gets payment } \\
\hline Goal in context & \multicolumn{2}{|c|}{ Cloud customer makes a payment for his consumption/contract. } \\
\hline Actors & \multicolumn{2}{|c|}{$\begin{array}{ll}- & \text { Provider Technical Manager (PTM) } \\
\text { - } & \text { Customer Technical Manager (CTM) } \\
\end{array}$} \\
\hline Precondition & \multicolumn{2}{|c|}{ Cloud customer and provider have a SLA. } \\
\hline Trigger & \multicolumn{2}{|l|}{ Payment for the service received } \\
\hline \multirow[t]{3}{*}{ Scenarios } & Scenarios Details & Data or Artifacts Exchanged \\
\hline & PTM sends an invoice for billing. & \\
\hline & CTM takes action for payment. & None \\
\hline Exceptions & \multicolumn{2}{|l|}{ None } \\
\hline
\end{tabular}

\section{Feedback Level Functions}

Generate Usage Patterns: In this function, a cloud customer tries to find a pattern of its use against time. With the understanding of its internal demand, a cloud customer can make changes in SLA or get multiple different type of contracts to maximizing its goal(s) (Table VIII). 
TABLE VIII. USE CASE TO GENERATE USAGE PATTERNS

\begin{tabular}{|c|c|c|}
\hline Use Case 8 & \multicolumn{2}{|l|}{ Generate Usage Patterns } \\
\hline Description & \multicolumn{2}{|c|}{$\begin{array}{l}\text { Customer Cloud Manager tries to generate a pattern of usage from historical data to reduce overprovisioning and also } \\
\text { underprovisioning. }\end{array}$} \\
\hline Goal in context: & \multicolumn{2}{|l|}{ Cloud customer finds a pattern from earlier consumption data. } \\
\hline Actors & \multicolumn{2}{|l|}{$\begin{array}{ll}\text { - } & \text { Customer Technical Manager (CTM) } \\
\text { - } & \text { Customer Business Manager (CBM) }\end{array}$} \\
\hline Precondition: & \multicolumn{2}{|c|}{ Cloud customer has been receiving service from cloud provider. } \\
\hline Trigger: & \multicolumn{2}{|l|}{ Identify usage pattern to reduce cost. } \\
\hline \multirow[t]{3}{*}{ Scenarios } & Scenarios Details & Data or Artifacts Exchanged \\
\hline & CTM Generates pattern of their consumption. & None \\
\hline & $\begin{array}{l}\text { CBM gets information from CTM so that s/he can update } \\
\text { SLA more efficiently. }\end{array}$ & None \\
\hline Exceptions & \multicolumn{2}{|l|}{ None } \\
\hline
\end{tabular}

\section{CONCLUSION}

In this paper, we have considered the problem of receiving a service in a cloud computing system. We propose a segregated interaction model to manage cloud service in a hierarchical way. The developed interaction model covers all the major functions in the defined system boundary. The presented model identifies the major decision makers for cloud management and their relationship and provides a segregation of system functions to approach the considered problem easily and effectively. At the end, the model analyses the system functions with the help of use cases. In future, data mining services can be incorporated in order to analyze usage patterns more effectively [14],[15],[16],[17].

\section{REFERENCES}

[1] Zhang, Q., Cheng, L. Boutaba, R.: Cloud computing: state-of-the-art and research challenges. Journal of Internet Services and Applications, Vol. 1(1), pp. 7-18 (2010).

[2] Armbrust, M., Fox, A., Griffith, R., Joseph, A.D., Katz, R. H., Konwinski, A., Lee, G., Patterson, D., Rabkin, A., Stoica, I., Zaharia, M.: A view of cloud computing. Communications of the ACM, Vol. 53(4), pp. 50-58 (2010).

[3] Armbrust, M., Fox, A., Griffith, R., Joseph, A.D., Katz, R. H., Konwinski, A., Lee, G., Patterson, D., Rabkin, A., Stoica, I., Zaharia, M.: Above the Clouds: A Berkeley View of Cloud Computing. Technical Report, EECS Department, U.C. Berkeley (2009).

[4] Avram, M. G.: Advantages and Challenges of Adopting Cloud Computing from Enterprise Perspective. Procedia Technology, Vol. 12(1), pp. 529-534 (2014).

[5] Yeo, C. S., Venugopal, S., James Broberg, J., Buyya, J. B. R.: Cloud computing and emerging IT platforms: Vision, hype, and reality for delivering computing as the 5th utility. Future Generation Computer Systems, Vol. 25, No. 6, pp. 599-616 (2009).
[6] Xu C. T. S., Xin, M. T. W.: Benefits and Challenges of the Adoption of Cloud Computing in Business. International Journal on Cloud Computing: Services and Architecture, Vol. 6, No. 6, pp.1-15 (2016).

[7] Gartner: Forecast: Public Cloud Services. Worldwide and Regions, Industry Sectors 2009-2014, (2010).

[8] Mell, P., Grance, T.: The NIST Definition of Cloud. National Institute of Standards and Technology, Information Technology Laboratory, Retrievedon September 15, 2011,from http://csrc.nist.gov/publications/nistpubs/800-145/SP800-145.pdf.

[9] Definition of SOA, http://www.opengroup.org/soa/soa/def.htm, last accessed 2011/08/15.

[10] Imran, A.: An Overview of Service Models of Cloud Computing. International Journal of Multidisciplinary and Current Research, Vol. 2, pp. 779-783 (2014).

[11] Malan, R., Bredemeyer, D.: Functional requirements and use cases. Bredemeyer Consulting, Retrieved on August 11, 2011 from http://www.bredemeyer.com/pdf_files/ functreq.pdf, (2001).

[12] Saravanan, K., Rajaram, M.: An Exploratory Study of Cloud Service Level Agreements - State of the Art Review. KSII Transaction of Internet and Information System, Vol. 9, No. 3, (2015).

[13] Aljoumah, E., Al-Mousawi, F., Ahmad, I., Al-Shammri, M., Al-Jady, Z.: Cloud Computing Architectures: A Comprehensive Study. International Journal of Grid Distribution Computing, Vol. 8, No. 5, pp. 7-32 (2015).

[14] Adnan M. N.: On Dynamic Selection of Subspace for Random Forest. The 10th International Conference on Advanced Data Mining and Applications (ADMA 2014), pp. 19 - 21 (2014).

[15] Adnan M. N., Islam M. Z.: ComboSplit: Combining Various Splitting Criteria for Building a Single Decision Tree. The International Conference on Artificial Intelligence and Pattern Recognition (AIPR), pp. 17 - 19 (2014).

[16] Adnan, M. N., Islam, M. Z.: ForEx++: A new framework for knowledge discovery from decision forests. Australasian Journal of Information Systems, Vol. 21, pp. 1-20 (2017).

[17] Adnan, M. N., Islam, M. Z.: Forest PA: Constructing a decision forest by penalizing attributes used in previous trees. Expert Systems with Applications, Vol. 89, pp. 389-403 (2017). 